\title{
CRITERIA FOR SPECIES AND THEIR SUB- DIVISIONS FROM THE POINT OF VIEW OF GENETICS
}

\author{
$\mathrm{BY}$ \\ W. Frank Blair \\ University of Michigan, Ann Arbor, Michigan
}

\section{INTRODUCTION}

The problem of the evolution of species has been much clarified in recent years. Progress has been possible principally because the data from the separate disciplines of genetics, ecology, biogeography, and morphology all have been brought to bear on the problem. The present discussion pertains to the evolution and classification of the vertebrates. The evidence to be presented is mostly from the field of mammalogy, partly because of the author's specialization in that field and partly because of recent progress toward an understanding of the evolution of mammalian species.

Most modern geneticists, with the notable exception of Goldschmidt (1940), agree that species develop through isolation and the gradual accumulation of minor mutations in the isolated stocks. These mutations, of course, may affect the physiology of the stocks as well as their physical characters. This is speciation through microevolution. The opposing view of Goldschmidt, that species arise by macroevolution-that is, through sudden, major, or systemic mutations-cannot be discussed here for want of time. Suffice it to say, however, that most geneticists are convinced that speciation occurs through microevolution and that the evidence to be presented here supports this view.

\section{RACIATION}

Most species of vertebrates, if they are at all widespread, are divisible into numerous geographical races. Many of the more obvious of these races have been named; they constitute the subspecies of vertebrate systematists. Each geographical race is in contact with one or more other races of the same species. These races are fertile each with the others (Dice, 1933), and along the contacts they form intergrading populations. Where contact is prevented by ecological barriers, the races concerned are connected by intergradation through chains of races. 
Consequently, a mutation that arises in any geographical race theoretically could be dispersed ultimately to all of the other races.

The differences between geographical races are hereditary, and the genetic differences between races are no different than those between individuals. This first was proved by Sumner (1932) and later confirmed by Dice (1937 and other papers). There is some evidence (author's unpublished data) that the tremendous raciation in at least one species (Peromyscus maniculatus) involves but a relatively small number of genes. How then do we account for the existence of numerous geographical races if the stock of genes is relatively small and there is the opportunity for transfer of these genes to all parts of the interbreeding population? The logical explanation is that geographical races indicate ecological trends (Dice and Blossom, 1937). From the stock of genes available in the entire population of the species or incipient species, selection has, in any given environment, weeded out the genes that are non-adaptive for that environment and has conserved those that are adaptive. Selection pressure will act to maintain the most successful genetic combination in spite of gene mutation and the spread of genes from other races of the same species.

As the environment varies geographically so will the most successful gene complexes vary geographically. The geographical races that have been named represent, for the most part, major ecological trends. Within the area of one of these major trends many minor variations in environment occur, and, likewise, many local variations in gene complexes (see Dice, 1940a). Thus, a geographical race usually is but a part of the species population that is adapted to a particular environment, and many locally adaptive variations may occur within its limits. Geographical races also may be produced as a result of the random drifting apart of small, partially isolated colonies (Wright, 1931).

Raciation and speciation are distinctly different evolutionary processes. Geographical races are not necessarily incipient species (Dice and Blossom, 1937; Goldschmidt, 1940; Wright, 1940). The process of speciation is initiated by the isolation of a part of the previously interbreeding population. The part of the population becoming isolated might conceivably comprise a geographical race, but it might comprise, instead, only a part of a geographical race or several races. If the split did occur along racial lines there would be an illusion of rapid divergence because of the initially different gene complexes of the two populations. However, there is no reason whatsoever for believing that under such conditions isolating mechanisms would be developed any more rapidly or that 
infertility would appear any sooner than if the split had occurred independently of racial lines.

\section{SPECIATION}

Speciation occurs as the result of : (1) isolation of one or more parts of a previously interbreeding population, (2) morphological differentiation as the result of differential mutation and selection pressure, and (3) the development of mutual infertility through genic or chromosomal changes.

The process of species differentiation is reversible up to the point at which the diverging populations become so different genetically that the interchange of genes is no longer possible. Geographical barriers may be overcome by the spreading out of one or the other of previously isolated populations until the two populations merge. Ecological isolation may break down. A. P. Blair (1941) believes that man-made ecological changes account in part for the present hybridization in nature of certain toad populations. These previously had so diverged morphologically and ecologically as to be ranked as taxonomic species. He suggests that this may be a case of fusion and disintegration of species. Psychological barriers are only relatively effective, and they may be overcome under certain conditions of population pressure. Hubbs and Hubbs (1932) believes that hybridization of sunfishes occurs as the result of intensive population pressure and limited spawning grounds in certain types of pools. Miller (1941) found numerous instances of hybridization of juncos due to the partial failure of one or more of these isolating mechanisms.

To maintain a completely dynamic point of view, we must remember that the process of speciation can be reversed so long as isolation is maintained only by geographical, ecological, or psychological barriers. One of these isolating mechanisms or a combination of several may operate at any one moment to effectively bar the interchange of genes between two incipient species, but there is no certainty that future events will not break down the barrier. It is only when the interchange of genetic material between the populations is made impossible by infertility that an irrevocable step in speciation is taken.

The conventional taxonomic system obviously does not distinguish between the differentiating populations that have, and those that have not, passed the point of irreversibility. A dynamic system of classification is needed, therefore, to show the evolutionary relationships of these natural populations. We propose to utilize such a system here. In this system, the criteria for discriminating between the different classificatory units are genetic. Strictly speaking, these criteria concern the 
ability of different evolutionary units to exchange germinal materials with other units. Applying these criteria, we have two categories of species populations: (1) those that are isolated from all other populations by reason of sterility and (2) those that are isolated at any given moment by mechanisms short of intersterility.

Incipient species - that is, diverging populations that have not yet attained intersterility-we propose to call just what they are, incipient species. As we define it, an incipient species is a natural population that is at least partially fertile with some other population but is inhibited from breeding with it by some isolating mechanism or mechanisms. For populations that have reached intersterility, a satisfactory term already exists in botanical literature. The cenospecies as proposed by Turesson (1922) and used by Gregor, Davey, and Lang (1936), Clausen, Keck, and Hiesey (1939), and others corresponds to this category in our system of classification. The cenospecies, as redefined here to apply to animals as well as plants, is a natural population that is infertile (can produce only sterile hybrids or none at all) with every other population.

In setting up a dynamic system of classification that is complementary to the orthodox system instead of attempting to change the latter system to fit the experimental data, we have followed the example of the experimental botanists. These workers probably followed a wise course in not attempting to revise the orthodox system during the early stages of experimental taxonomic research. However, such a course merely postpones the day when a major revision of the conventional taxonomic system must be made to utilize the criteria furnished by the experimental method. It seems to the present author that the problem of revision is one for the taxonomist.

The incipient species of our classification corresponds in many, but not all, cases to the taxonomic species. The cenospecies, likewise, corresponds in many, but not all, cases to the species-group, an informal category, of systematic mammalogy. However, some taxonomic species are conterminous with the cenospecies. Until such time as the conventional system of classification is revised to use the criteria furnished by the experimental method, the term species must be restricted to museum species, that is those species units based on morphological and geographical criteria alone. It should be kept in mind that these museum species do not necessarily represent evolutionary units. The terms incipient species and cenospecies are to be used only when the evolutionary relationships of the populations concerned have been established by experiment.

A nomenclatorial problem arises here, because no formal category of the order of the cenospecies is recognized in orthodox systematics. In 
the following discussion the name of each cenospecies is made to coincide with the first formally recognized species name within its limits. This usually corresponds to the name of the species-group as used informally in mammalian taxonomy.

\section{Speciation in Peromyscus}

The species-group of mammalian taxonomists has been shown by experiment to fit our definition of a cenospecies in at least some cases. Dice (1933) has shown that in all crosses attempted between subgroups of a species-group at least some fertile offspring were produced, but no offspring were obtained in attempted crosses between species-groups.

Speciation in Peromyscus has been studied more intensively than in any other group of mammals, due primarily to the early work of Sumner (1932, for list of publications) and the work of Dice (1940a, and numerous other papers) and his collaborators. Nine apparent cenospecies of Peromyscus occur in North America north of Mexico. Four of these cenospecies, californicus, crinitus, nuttalli, and floridanus, have no subgroups of significance in speciation, although most have undergone some raciation. Two other cenospecies, boylii and eremicus, are each split into two apparently separate breeding arrays, each with its own geographic races. In the first of these cases, the two arrays, boylii and pectoralis, occur together in the same regions and in the same ecological communities. However, the fertility relationships in this case, and in the case of the two subgroups of eremicus, eremicus and merriami, are as yet obscure. The three remaining cenospecies of Peromyscus have provided most of our evidence about the course of speciation in this genus.

The cenospecies leucopus is split into two separate breeding arrays, which have been named, respectively, leucopus and gossypinus. The range of leucopus extends from southern Mexico north to Montana and east to Nova Scotia, but it does not extend into southern Alabama, Georgia, South Carolina, nor into any part of Florida. On the other hand, gossypinus ranges from Florida west to eastern Oklahoma and Texas, north to Tennessee, and east to southern Virginia. The ranges of the two populations overlap in a broad strip extending from eastern Texas and Oklahoma to Virginia. The leucopus and gossypinus cross freely in the laboratory and produce fertile offspring (Dice, 1937a). However, Dice (1940b) found no evidence of hybridization between the two arrays where they occurred together in the Dismal Swamp region. Osgood (1909) found in museum materials no evidence of hybridization of the two, and consequently treated them as taxonomically distinct species. 
The leucopus and gossypinus arrays constitute two separate incipient species in our system of classification. The two arrays combined comprise a cenospecies, which is recognized to be split into the two diverging populations. The separation of the two populations probably occurred in the not distant geological past. The gossypinus population could possibly have become separated from the parent leucopus-gossypinus population during one of the Pleistocene inter-glacial periods, when, due to a raised sea-land, much of the peninsula of Florida existed as a large island (see Cooke, 1939). When, with a lowering of the sea level, this island again became connected with the mainland the opportunity arose for this population to spread out over the southeastern coastal plain. Today, this spreading has reached the point where the two populations overlap broadly. During the course of the separation, however, the two populations have diverged morphologically to the extent that they differ in the size of certain parts of the body. The morphological differences between the two arrays, however, are no greater than those that exist between some races of the leucopus array. The most important divergence between the two populations, though, seems to have been a psychological one. This acts as an isolating mechanism to prevent interbreeding now that the home ranges of the two arrays overlap. So long as this isolating mechanism effectively prevents interchange of genes between the two populations the two are free to drift apart through differential mutation and selection. No infertility yet exists between the two, however, so the process of differentiation still is reversible. The psychological chasm between them possibly may yet be bridged under some conditions of population pressure. In our classification, the populations of leucopus and gossypinus, therefore, are to be considered incipient species.

The cenospecies maniculatus is broken into several apparently discrete breeding arrays. The genetic relationships of only two of these arrays, maniculatus and polionotus have been investigated. The maniculatus population ranges over most of North America from southern Mexico to Alaska and Labrador, but like the leucopus array of the cenospecies leucopus it does not range into the southeastern corner of the United States. It is replaced there by a geographically isolated, morphologically differentiated array, polionotus. The separation of these two arrays within the cenospecies maniculatus probably was brought about by the same event that split the cenospecies leucopus into two separate populations. Actually, the polionotus array comprises not one geographically isolated breeding population but three or more, for populations of these mice occur on at least two islands. The island populations are as effectively isolated 
from the mainland population as that population is from the maniculatus array. The island populations, the subspecies leucocephalus and plasma of systematic mammalogy, must be considered incipient species under our system, just as the mainland population must be considered such.

The fertility relations of these populations, in so far as we know them, are extremely interesting. The mainland population of polionotus crosses with the maniculatus population in the laboratory and produces fertile offspring (Watson, 1942). Furthermore, the leucocephalus population from Santa Rosa Island, Florida, crosses readily with the mainland population of polionotus and produces fertile offspring (Sumner, 1930). It would seem, thus far, that no infertility has appeared between any of these incipient species. However, in crosses in which a laboratory stock combining the germinal materials of the Santa Rosa Island and mainland populations was mated with representatives of the maniculatus array some unexpected results were obtained (author's unpublished data). Only a few of the matings produced offspring. The $F_{1}$ animals were only partially viable, and many died shortly after birth. The sex ratio was unbalanced significantly in favor of females. The $F_{1}$ females were fertile, but both fertile and sterile $F_{1}$ males were produced. The sterility of some $F_{1}$ males appears to be due to gross disturbances in spermatogenesis (this is being investigated by Moree, unpublished). The logical explanation is that the leucocephalus population contributed the partial infertility with maniculatus, since the mainland polionotus population has proved fertile in crosses with maniculatus. This is being further investigated by crossing pure leucocephalus mice with maniculatus.

If our assumption is correct that the partial infertility in the abovementioned cross came from the leucocephalus population, then that population has diverged farther from the maniculatus array than has the mainland polionotus population. Physically, the differences exhibited by the polionotus, leucocephalus and maniculatus populations are no greater than the differences between some of their geographic races.

The leucocephalus population differs genetically from maniculatus in at least one important adaptive character. A single unit factor for the dorsal extension of ventral white (white cheek, in author's unpublished data) is dominant over the "normal" condition found in maniculatus. There also is, in leucocephalus, a series of modifiers that act to extend the white progressively farther and farther onto the dorsal surface (see Sumner, 1930). All leucocephalus that have been examined are, phenotypically at least, white cheek, and all representatives of the maniculatus array are "normal." In the mainland polionotus population, littoral races are genetically white cheeked, while interior races are "normal." 
If, in the course of future events, leucocephalus should develop complete infertility with maniculatus and the mainland polionotus population should become extirpated, then the great difference between the white cheeked leucocephalus and the "normal" maniculatus would constitute one of the so-called "bridgeless gaps" on the basis of which Goldschmidt (1940) attempts to discredit speciation through microevolution. The gap would be bridgeless, of course, only at that hypothetical future date and only after the connecting links had disappeared.

The cenospecies truei affords the last example of speciation in progress that we will discuss. In the southwestern United States this cenospecies is split into two distinct breeding arrays, the taxonomic species truei and nasutus, each with several geographic races. The geographic ranges of these two arrays overlap broadly, and in many places the two occur together in the same ecological associations (Dice, 1942). The two arrays can be separated easily on the basis of morphological characters, of which the most distinctive are the size of the external ear, size of the auditory bullae, and relative length of the tail. Representatives of the two arrays can be crossed in the laboratory. The $F_{1}$ females are fertile, but the $F_{1}$ males all are sterile (Dice, 1937b). No hybrids between the two have been found in nature. It seems evident, therefore, as Dice (1942) has pointed out that some psychological barrier must prevent breeding between the two populations.

The truei and nasutus populations represent a closer approach to mutual infertility, and consequently to the irreversible stage in speciation, than is evident in the other cases of incipient speciation that we have discussed. The lowest stage of speciation in our material has been reached by the leucopus and gossypinus arrays, which, apparently while geographically isolated, have diverged morphologically and have developed a psychological barrier sufficient to prevent interbreeding now that the populations are in contact. The divergence between the maniculatus and polionotus populations is of approximately the same order, and so is that between polionotus and leucocephalus. The differentiation between the leucocephalus and maniculatus represents a further step in speciation, for partial infertility has developed. The truei and nasutus populations represent a still further step, for in this case all hybrid males are sterile. When the hybrid females, too, become sterile the divergence of these populations one from the other will have passed the point from which there is no turning back. However, until that point is reached there always is the possibility that the psychological isolating mechanisms may break down and thus permit the fusion of the two 
populations. Therefore, truei and nasutus still are but incipient species under our dynamic system of classification.

The incipient species of Peromyscus exhibit several noteworthy evolutionary trends. In the two cenospecies leucopus and maniculatus, geographic isolation appears to have been the first step in speciation. The evidence admittedly is circumstantial, but it seems clearly indicated that within these cenospecies "physiological isolating mechanisms" (see Dobzhansky, 1941: 257) were developed only after geographic isolation had taken place. If these cases are representative, then geographic isolation is of paramount importance in speciation. A similar view of the importance of geographical isolation is held by Miller (1941) in respect to speciation in juncos. The principal morphological differences in the diverging populations, both in leucopus and maniculatus, are in size alone and apparently are non-adaptive. The morphological differences between the diverging arrays of the cenospecies truei, which represent later stages of speciation, are differences of proportion as well as of size, and probably are in part adaptive. There is at least a suggestion, therefore, that the first divergence in isolated populations may be due to chance drifting apart in non-adaptive characters.

\section{SUMMARY}

Geographical races usually indicate ecological trends; hence they are not necessarily incipient species. Speciation comes about through the isolation, differentiation, and ultimate intersterility of parts of a previously interbreeding population. The process of speciation is reversible up to the point at which the exchange of genes becomes no longer possible because of intersterility.

In a system of classification that makes use of genetic and ecological criteria, the cenospecies is defined as a population that is infertile with every other population. Any isolated population that has not evolved far enough to be infertile with related populations is regarded as an incipient species. Such a system shows relationships and evolutionary trends better than does the conventional taxonomic method.

Blair, A. P.

\section{LITERATURE CITED}

1941. Variation, isolation mechanisms, and hybridization in toads. Genetics 26: 398-417, 6 figs.

Clausen, J., Keck, D. D., \& Elesey, W. M.

1939. The concept of species based on experiment. Amer. Jour. Botany 26 : 103-106.

Cooke, C. $\mathbf{W}$.

1939. Scenery of Florida interpreted by a geologist. Fla. Geol. Bull. 17: 1-118, 58 figs. 
Dice, L. R.

1932. Variation in a geographic race of the deer-mouse, Peromyscus maniculatus bairdii. Occes. Pap. Univ. Mich. Mus. Zool. 239: 1-26, 1 fig.

1933. Fertility relationships between some of the species and subspecies of mice in the genus Peromyscus. Jour. Mammalogy 14: 298-305.

1937 a. Fertility relations in the Peromyscus leucopus group of mice. Contr. Lab. Vert. Genetics 4: 1-3.

1937b. Partial infertility between two members of the Peromyscus truei group of mice. Contr. Lab. Vert. Genetics 5: $1-4$.

1940a. Ecologic and genetic variability within species of Peromyscus. Amer. Nat. 74: 212-221.

1940b. Relationships between the wood-mouse and cotton-mouse in eastern Virginia. Jour. Mammalogy 21: 14-23, 1 fig.

1942. Ecological distribution of Peromyscus and Nèotoma in parts of southern New Mexico. Ecology 23: 199-208, 1 fig.

Dice, L. R., \& Blossom, P. M.

1937. Studies of mammalian ecology in southwestern North America with special attention to the colors of desert mammals. Carnegie Inst.' Wash. Publ. 485: $\mathrm{i}-\mathrm{iii}+1-129,8$ figs., 8 pls.

Dobzhansky, $\mathbf{T}$.

1941. Genetics and the origin of species. New York: xviii+446 pp., 24 figs.

Goldschmidt, R.

1940. The material basis of evolution. New Haven: xi+436 pp., 83 text figs.

Grogor, J. W., Davey, v. M., \& Lang, J. M. S.

1936. Experimental taxonomy. I. Experimental garden technique in relation to the recognition of the small taxonomic units. New Phytologist 35: 323-350, 3 figs.

Hubbs, C. L., \& Hubbs, Laura C.

1932. Experimental verification of natural hybridization between distinct genera of sunfishes. Papers Mich. Acad. Sci., Arts, Letters 16: 427-437.

Miller, A. H.

1941. Speciation in the avian genus Junco. Univ. Calif. Publ. Zool. 44: 173434, 33 figs.

Osgood, W. H.

1909. Revision of the mice of the American genus Peromyscus. North Amer. Fauna 28: 285 pp., 12 figs., 8 pls.

Sumner, F. B.

1930. Genetic and distributional studies of three subspecies of Peromyscus. Jour. Genetics 23: 275-376, 27 figs., 11 pls.

1932. Genetic, distributional, and evolutionary studies of the subspecies of deer mice (Peromyscus). Bib. Genetica 8: 1-106, 24 figs.

Turesson, G.

1922. The genotypical response of the plant species to the habitat. Hereditas 3: 341-347.

Watson, M. L.

1942. Hybridization experiments between Peromyscus polionolus and Peromyscus maniculatus. Jour. Mammalogy 23: 315-316.

Wright, $\mathbf{s}$.

1931. Evolution in mendelian populations. Genetics $16: 97-159,21$ figs.

1941. The material basis of evolution (review). Sei. Monthly 68: 165-170. 